\title{
Associations Between Fast-Food Consumption and Body Mass Index: A Cross-Sectional Study in Adult Twins
}

\author{
Hannah Cohen-Cline, ${ }^{1}$ Richard Lau, ${ }^{2}$ Anne V. Moudon, ${ }^{3}$ Eric Turkheimer, ${ }^{4}$ and Glen E. Duncan ${ }^{1,2}$ \\ ${ }^{1}$ Department of Epidemiology, School of Public Health, University of Washington, Seattle, WA, USA \\ ${ }^{2}$ Nutritional Sciences Program, University of Washington, Seattle, WA, USA \\ ${ }^{3}$ Urban Form Laboratory, Department of Urban Design and Planning, University of Washington, Seattle, WA, USA \\ ${ }^{4}$ Department of Psychology, University of Virginia, Charlottesville, VA, USA
}

\begin{abstract}
Obesity is a substantial health problem in the United States, and is associated with many chronic diseases. Previous studies have linked poor dietary habits to obesity. This cross-sectional study aimed to identify the association between body mass index (BMI) and fast-food consumption among 669 same-sex adult twin pairs residing in the Puget Sound region around Seattle, Washington. We calculated twin-pair correlations for BMI and fast-food consumption. We next regressed BMI on fast-food consumption using generalized estimating equations (GEE), and finally estimated the within-pair difference in BMI associated with a difference in fast-food consumption, which controls for all potential genetic and environment characteristics shared between twins within a pair. Twin-pair correlations for fast-food consumption were similar for identical (monozygotic; MZ) and fraternal (dizygotic; DZ) twins, but were substantially higher in MZ than DZ twins for BMI. In the unadjusted GEE model, greater fast-food consumption was associated with larger BMI. For twin pairs overall, and for $\mathrm{MZ}$ twins, there was no association between within-pair differences in fast-food consumption and BMI in any model. In contrast, there was a significant association between within-pair differences in fast-food consumption and BMI among DZ twins, suggesting that genetic factors play a role in the observed association. Thus, although variance in fast-food consumption itself is largely driven by environmental factors, the overall association between this specific eating behavior and BMI is largely due to genetic factors.
\end{abstract}

Keywords: body mass index, fast-food consumption, twin studies, generalized estimating equations

Over one-third of adults and approximately $17 \%$ of children in the United States are currently obese according to BMI $\left(\mathrm{kg} / \mathrm{m}^{2}\right)$ standards (Centers for Disease Control and Prevention, 2014). Obesity is linked to multiple chronic health problems including type 2 diabetes, sleep apnea, liver disease, cardiovascular disease, and some forms of cancer (National Task Force on the Prevention and Treatment of Obesity, 2000). Poor dietary habits, including increased consumption of meals at fast-food restaurants, have been linked to obesity (Larson et al., 2011a). Indeed, the rise in fast-food consumption has closely mirrored the rise in obesity in the United States (Powell et al., 2007). Consequently, there have been efforts to intervene on the potential contribution of the fast-food industry to obesity through methods such as menu labeling legislation that would require these restaurants to post the nutritional and caloric content of all food and beverage items (Roberto et al., 2010).

Although fast-food consumption has been linked to obesity in multiple studies, any attempt to link the exposure and outcome must account for factors that also affect consumption patterns and obesity status, such as socio-demographic factors, physical activity level (Colley et al., 2010), other dietary patterns including fruit and vegetable consumption (Cutler et al., 2012), and access to food sources such as fastfood restaurants, and supermarkets or grocery/convenience stores in the residential environment (Gordon-Larsen et al., 2006). Even in studies that adjust for such variables, concerns about unmeasured factors remain.

Genetic factors influence both obesity risk and the adoption of health behaviors (Choquet \& Meyre, 2011; Comuzzie

RECEIVED 6 December 2014; ACCEPTED 21 April 2015. First published online 25 May 2015.

ADDRESS FOR CORRESPONDENCE: Hannah Cohen-Cline, University of Washington, Department of Epidemiology, 1959 NE Pacific Street, Health Sciences Building F-250, PO Box 357236, Seattle, WA 98195-7236, USA. E-mail: hannahcc@u.washington.edu 
\& Allison, 1998; Perusse et al., 2003). The heritability of BMI is estimated to be between 24 and $90 \%$, with increasing age post-adolescence associated with decreasing heritability (Dubois et al., 2012; Elks et al., 2012; McCaffery et al., 2009; Min et al., 2013). Animal and human studies investigating the genetic basis for obesity have identified over 500 candidate genes (O'Rahilly \& Farooqi, 2008; Vimaleswaran et al., 2012). Studies have further shown that genetic factors can interact with behavior and lifestyle factors to influence obesity risk. In particular, diet and physical activity can mitigate or accentuate genetic susceptibility to obesity (Ahmad et al., 2013; Cauchi et al., 2009; Corella et al., 2012; Heitmann et al., 1997; Lee et al., 2010; McCaffery et al., 2009; Mustelin et al., 2009; Rampersaud et al., 2008; Scott et al., 2010; Sonestedt et al., 2009).

The use of the twin design can address the problems of confounding or interaction by genetic factors. For example, Nelson et al. (2006), investigating twins raised together as a part of the National Longitudinal Study of Adolescent Health (Add Health), reported that identical twins had greater within-pair correlations for BMI, physical activity and fast-food consumption than fraternal twins, indicating genetic influences on these behaviors and health outcomes (Nelson et al., 2006). Further, among both identical and fraternal twins, within-pair correlations in behavior differed between twins who still lived together and twins who lived apart, indicating the presence of external environmental influences on behavior (Nelson et al., 2006).

The objective of this study was to examine the association between BMI and fast-food consumption among a sample of adult twins from a community-based twin registry. We hypothesized that fast-food consumption was independently associated with BMI both between and within adult twin pairs.

\section{Materials and Methods Sample}

This cross-sectional analysis included 669 same-sex twin pairs from the University of Washington Twin Registry (UWTR), a community-based registry of adult twins reared together. Construction methods appear elsewhere (Afari et al., 2006; Strachan et al., 2013); briefly, adult twins are identified by the Washington State Department of Licensing and invited to join the registry. Surveys administered to registry members between 2006 and 2011 included items on socio-demographics, health conditions, and lifestyle behaviors. Standard questions about childhood similarity that determine zygosity with greater than $90 \%$ accuracy when compared with DNA-based methods were used to classify twins as identical (MZ) or fraternal (DZ; Eisen et al., 1989; Spitz et al., 1996; Torgersen, 1979). Of the 669 pairs in the study sample, $25 \%(N=168$ pairs $)$ are DZ.

Only same-sex twin pairs were used in the analysis, to limit the potential confounding effects of sex stemming from associations between sex and BMI among DZ twins. The majority (64\% or 429 pairs) of the sample is female. All twins resided within the Urban Growth Boundary of the four counties that comprise the Puget Sound region around Seattle, Washington: King, Kitsap, Pierce, and Snohomish counties.

\section{Measures}

The primary outcome was continuous BMI $\left(\mathrm{kg} / \mathrm{m}^{2}\right)$ derived from self-reported height and weight. In a separate study, self-reported BMI and directly measured BMI were highly correlated $(r=0.98, p<.01)$ among 200 UWTR twin pairs.

The primary exposure was fast-food consumption, collected using the following question based on the Project EAT survey: 'During the past four weeks, how many times in a typical week did you eat a meal at a fast-food restaurant such as McDonalds, Burger King, or KFC?'. Answers were recorded as $0,1-2,3-4$, and 5 or more times per week (Larson et al., 2011b; Neumark-Sztainer et al., 2011; 2012).

Covariates included age, sex, race (categorized as White or Other), household income (eight categories beginning with 'less than $\$ 20,000$ ', and increasing by increments of $\$ 10,000$ to 'greater than or equal to $\$ 80,000$ '), education (five categories including: 'completed grades 1-8', 'completed grades 9-11', 'high school graduate/GED', 'some college', and 'Bachelor's degree or higher'), physical activity (see description below), and residential street address to derive an objective measure of 'neighborhood' fast-food restaurant density.

Twins were asked to report the number of days during a typical week they exercised moderately for at least $30 \mathrm{~min}$ and vigorously for at least $20 \mathrm{~min}$. We multiplied their responses (frequency) by 30 and 20 (duration) for moderate and vigorous activity categories, respectively, and summed them to estimate total moderate-to-vigorous physical activity (MVPA, minutes per week). This measure stems from the current recommended activity levels for U.S. adults (i.e., 30 min of moderate-intensity activity 5 or more days per week and $20 \mathrm{~min}$ of vigorous-intensity activity 3 or more days per week, or some combination that achieves an energy expenditure of at least 500-1,000 metabolic equivalent minutes per week; Garber et al., 2011). In a sample of 104 twins who wore accelerometers and GPS devices over a 2-week period in an ongoing study (R01 AG042176), self-reported MVPA correlated with objectively measured MVPA $(r=0.46$, $p<.01$ ), indicating moderate validity.

Information on the presence of fast-food restaurants was obtained from the commercially available InfoUSA data base (obtained January 2012). Fast-food establishments were classified as chains that sell inexpensive, quickly served foods, and do not have table service, based on definitions from the North American Industry Classification System. Fast-food restaurant density was calculated in ArcGIS 9.3.1 to identify the number of fast-food restaurants within a 
3-km network-based buffer around each twin's geocoded street address.

\section{Statistical Analysis}

Fast-food consumption was converted to a continuous variable for our primary analyses. We substituted midpoint numbers for the range provided in each ordinal response category (e.g., 0, 1.5, 3.5, and 7). The final category, five or more times per week, was assigned the value seven based on data from the National Health and Nutrition Examination Survey related to frequency of fast-food consumption among U.S. adults, indicating that approximately twothirds of adults who ate fast-food five or more times per week did so between six and eight times (US Department of Health and Human Services, 2009).

Although the main goal of our analysis is to understand the bivariate relation between fast-food consumption and BMI, for descriptive purposes we first used a simple structural equation model in MPlus to estimate (maximum likelihood), calculated MZ and DZ twin-pair correlations for BMI and fast-food consumption, and to partition the phenotypic variance for both our predictor and outcome variables into three components: additive genetic $(\mathrm{A})$; the common environmental component (C); and unique environment (E); (Boomsma et al., 2002).

We used two statistical methods described by Carlin et al. (2005) to test associations between fast-food consumption and BMI in the twin data. We first regressed BMI on fastfood consumption using GEE with an identity link and an independent correlation matrix. This method estimates the population-averaged effect, treating twins as individuals and accounting for the correlation in twin data that would otherwise bias standard error estimates. Second, we calculated within-pair differences for the exposure, outcome, and all covariates. Using these within-pair differences, we regressed BMI on fast-food consumption, constraining the model to pass through the origin. This method estimates the within-pair difference in BMI associated with a difference in fast-food consumption, controlling for all potential genetic, and familial environment characteristics shared between twins within a pair. We report results for twins overall, as well as stratified by zygosity.

Finally, we performed a sensitivity analysis to explore if the form of the independent variable had any effect on our inferences about the dependent variable based on the GEE analysis. Fast-food consumption was included in the model as a series of 'dummy' variables across all ordinal response categories $(0,1-2,3-4,5$ or more). We also examined fast-food consumption as a binary variable (none/any) by combining the final three groups into a single category.

For all analyses, we estimated regression coefficients for four different models. The first model was unadjusted; all subsequent models were adjusted sequentially for covariates a priori thought to be confounders in the fast-food consumption-BMI association. Model 2 was adjusted for socio-demographic factors; model 3 additionally for MVPA; and model 4 additionally for fast-food restaurant density in the residential neighborhood. For the twin differences model, we did not need to adjust for age, sex, or race because these characteristics do not differ between twins within a pair but we did sequentially adjust for income/education, MVPA, and fast-food restaurant density.

Statistical analysis was performed using STATA Release 11 (StataCorp, College Station, TX).

\section{Results}

Select characteristics of the sample are provided in Table 1, stratified by fast-food consumption (none vs. any). Among twins reporting any fast-food consumption, the average was $2.1 \pm 1.4$ meals per week. Compared to those who reported eating any fast-food, respondents who reported no fastfood consumption were more likely to be female (67\% vs. $61 \%$ ), White ( 89 vs. $84 \%$ ), in the higher income categories ( $58 \%$ vs. $48 \%$ with an annual income of $\$ 50,000$ and above), have greater educational attainment ( $82 \%$ vs. $73 \%$ with at least some college education), spend more time in MVPA (141 $\mathrm{min} / \mathrm{wk}$ vs. $115 \mathrm{~min} / \mathrm{wk}$ ), and have lower BMIs (23 vs. $\left.26 \mathrm{~kg} / \mathrm{m}^{2}\right)$. However, there were no differences between groups with respect to age and residential fast-food restaurant density.

\section{Correlations and Heritability}

The within-pair correlations for BMI and fast-food consumption stratified by zygosity, and the A, C, and E components are given in Table 2. We also calculated the within-pair correlations stratified by sex. Among MZ twins, men and women had similar twin-pair correlations for BMI (men: 0.80, 95\% CI: 0.74, 0.85 ; women: $0.81,95 \%$ CI: $0.77,0.85$ ) and fast-food consumption (men: $0.38,95 \%$ CI: $0.25,0.50$; women: $0.36,95 \%$ CI: $0.26-0.45$ ). Among DZ twins, while men and women had similar correlations for fast-food consumption (men: 0.40, 95\% CI: 0.15, 0.60; women: 0.36, $95 \%$ CI: $0.19,0.51)$, men had a lower within-pair correlation than women for BMI (men: 0.27, 95\% CI: 0.01, 0.50; women: 0.46 , 95\% CI: $0.30-0.60$ ), though this difference was not statistically significant.

\section{Individual Twin Analysis (Generalized Estimating Equa- tions)}

In the unadjusted model, a one-unit greater difference in fast-food consumption (continuous variable, meals per week) was associated with a 0.62 -unit greater BMI ( $95 \%$ CI: 0.42, 0.82). Associations were attenuated, but remained significant when adjusting for potential confounders in sequential models; in the model fully adjusted for sex, age, race, income, education, physical activity, and fast-food restaurant density in the home neighborhood, a one-unit 
TABLE 1

Select Characteristics of the Sample by Level of Fast-Food Consumption, ${ }^{a}$ University of Washington Twin Registry, 2006-2011

\begin{tabular}{|c|c|c|c|c|}
\hline \multirow[b]{2}{*}{ Characteristic } & \multicolumn{2}{|c|}{$\begin{array}{l}\text { No fast-food } \\
(N=653)\end{array}$} & \multicolumn{2}{|c|}{$\begin{array}{l}\text { Any fast-food } \\
(N=685)\end{array}$} \\
\hline & $N$ & $\%$ & N & $\%$ \\
\hline Body mass index $\left(\mathrm{kg} / \mathrm{m}^{2}\right)^{b}$ & 23.9 & 4.3 & 26.1 & 6.4 \\
\hline Age $\left(\right.$ years) ${ }^{b}$ & 30.9 & 13.7 & 29.9 & 12.8 \\
\hline Sex & 439 & 67.2 & 419 & 61.2 \\
\hline White & 582 & 89.1 & 577 & 84.2 \\
\hline \multicolumn{5}{|l|}{ Income } \\
\hline$>\$ 50,000$ & 241 & 36.9 & 319 & 46.6 \\
\hline$\leqq \$ 50,000$ & 384 & 58.8 & 333 & 48.6 \\
\hline \multicolumn{5}{|l|}{ Education } \\
\hline Grades 1-8 & 0 & 0 & 2 & 0.3 \\
\hline Grades 9-11 & 23 & 3.5 & 29 & 4.2 \\
\hline High school/GED & 90 & 13.8 & 151 & 22.0 \\
\hline Some college & 249 & 38.1 & 304 & 44.4 \\
\hline Bachelor's degree or higher & 289 & 44.3 & 195 & 28.5 \\
\hline Physical activity (minutes per week) & 141.2 & 90.8 & 114.5 & 93.0 \\
\hline Fast-food restaurant densityb,d & 0.5 & 0.4 & 0.5 & 0.3 \\
\hline
\end{tabular}

\section{TABLE 2}

Within-Pair Correlations and Variance Component Estimates for Fast-Food Consumption ${ }^{\mathrm{a}}$ and Body Mass Index Among Same-Sex Twin Pairs, University of Washington Twin Registry, 2006-2011

\begin{tabular}{|c|c|c|c|c|}
\hline & \multicolumn{2}{|c|}{$\begin{array}{l}\text { Fast-food consumption } \\
\text { (meals per week) }\end{array}$} & \multicolumn{2}{|c|}{$\begin{array}{c}\text { Body mass } \\
\text { index }\left(\mathrm{kg} / \mathrm{m}^{2}\right)\end{array}$} \\
\hline & Correlation & $95 \% \mathrm{Cl}$ & Correlation & $95 \% \mathrm{Cl}$ \\
\hline \multicolumn{5}{|c|}{ Sibling correlations } \\
\hline$M Z$ & 0.373 & $0.302,0.444$ & 0.829 & $0.804,0.854$ \\
\hline $\mathrm{DZ}$ & 0.382 & $0.251,0.513$ & 0.398 & $\begin{array}{l}0.294,0.502 \\
0,0\end{array}$ \\
\hline ACE Estimates $^{\mathrm{b}}$ & & & & 0,0 \\
\hline$a^{2}$ & 0.000 & & 0.829 & $0.804,0.854$ \\
\hline$c^{2}$ & 0.375 & $0.312,0.438$ & 0.000 & \\
\hline$e^{2}$ & 0.625 & $0.562,0.688$ & 0.171 & $0.146,0.196$ \\
\hline
\end{tabular}

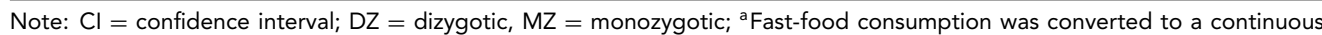
variable by substituting midpoint values for the range in each ordinal category $(0,1.5,3.5,7)$; ${ }^{b} \mathrm{ACE}$ estimates: additive genetic (A), variance attributable to the additive effect of individual genes; shared environmental (C), variance attributable to environmental influences shared by twins raised in the same family; and non-shared environmental (E), variance attributable to environmental influences unique to the individual. In this analysis the ACE estimates were constrained to keep the variance components non-negative.

greater difference in fast-food consumption was associated with 0.50-unit greater BMI (95\% CI: 0.29, 0.70).

\section{Within Twin Analysis (Twin-Differences)}

Table 3 provides results from the twin-differences approach. For twin pairs overall, there was no association between within-pair differences in fast-food consumption and within-pair differences in BMI in any model ( $p s>$ $.05)$. Likewise, there was no association between withinpair differences in fast-food consumption and BMI among MZ twins in any model ( $p s>.05$ ). In contrast, among DZ twins, the association between within-pair differences in fast-food consumption and BMI in the unadjusted model was significant $(0.74,95 \%$ CI: $0.32,1.16)$, and the association remained significant when adjusting for all covariates
(Table 3). The interaction term for zygosity was significant in all models ( $p s>.01)$

\section{Sensitivity Analysis (Individual Twin Analysis Using Generalized Estimating Equations)}

The positive association between fast-food consumption and BMI among individual twins reported above treated the exposure, fast-food consumption, as a continuous variable; this association was further examined using 'dummy' and binary categorizations of the exposure instead (Table 4). When expressing fast-food consumption as a categorical variable, with zero times per week as the reference group, greater consumption of fast-food was linearly associated with BMI in a dose-dependent manner (trend test, $p<$ .001). In the unadjusted model, compared to never eating fast-food, eating fast-food, 1-2 times per week was 
TABLE 3

Association Between Fast-Food Consumption ${ }^{\mathrm{a}}$ and Body Mass Index Within Same-Sex Twin Pairs Stratified by Zygosity, University of Washington Twin Registry, 2006-2011

\begin{tabular}{|c|c|c|c|c|c|c|c|c|}
\hline & \multicolumn{2}{|c|}{ Model $1^{b}$} & \multicolumn{2}{|c|}{ Model $2^{c}$} & \multicolumn{2}{|c|}{ Model $3^{d}$} & \multicolumn{2}{|c|}{ Model $4^{e}$} \\
\hline & Coefficient & $95 \% \mathrm{Cl}$ & Coefficient & $95 \% \mathrm{Cl}$ & Coefficient & $95 \% \mathrm{Cl}$ & Coefficient & $95 \% \mathrm{Cl}$ \\
\hline Overall fast-food consumption (meals per week) & 0.14 & $-0.06,0.33$ & 0.14 & $-0.07,0.34$ & 0.16 & $-0.06,0.37$ & 0.16 & $-0.05,0.37$ \\
\hline MZ fast-food consumption (meals per week) & -0.02 & $-0.25,0.21$ & -0.01 & $-0.24,0.22$ & 0.005 & $-0.23,0.24$ & 0.01 & $-0.23,0.24$ \\
\hline DZ fast-food consumption (meals per week) & 0.74 & $0.32,1.16$ & 0.74 & $0.31,1.18$ & 0.79 & $0.35,1.23$ & 0.80 & $0.36,1.25$ \\
\hline
\end{tabular}

\section{TABLE 4}

Sensitivity Analyses of the Association Between Fast-Food Consumption ${ }^{\mathrm{a}}$ and Body Mass Index Among Twins, University of Washington Twin Registry, 2006-2011

\begin{tabular}{|c|c|c|c|c|c|c|c|c|}
\hline & \multicolumn{2}{|c|}{ Model $1^{\mathrm{b}}$} & \multicolumn{2}{|c|}{ Model $2^{c}$} & \multicolumn{2}{|c|}{ Model $3^{d}$} & \multicolumn{2}{|c|}{ Model $4^{\mathrm{e}}$} \\
\hline & Coefficient & $95 \% \mathrm{Cl}$ & Coefficient & $95 \% \mathrm{Cl}$ & Coefficient & $95 \% \mathrm{Cl}$ & Coefficient & $95 \% \mathrm{Cl}$ \\
\hline \multicolumn{9}{|c|}{ Fast-food consumption (meals/wk) } \\
\hline 0 & Ref & & Ref & & Ref & & Ref & \\
\hline $1-2$ & 2.17 & $1.55,2.79$ & 2.12 & $1.51,2.74$ & 2.04 & $1.42,2.67$ & 2.05 & $1.43,2.68$ \\
\hline $3-4$ & 2.25 & $1.10,3.40$ & 1.92 & $0.78,3.06$ & 1.79 & $0.64,2.94$ & 1.80 & $0.66,2.95$ \\
\hline $5+$ & 3.12 & $1.42,4.83$ & 2.61 & $0.95,4.27$ & 2.38 & $0.70,4.05$ & 2.39 & $0.71,4.06$ \\
\hline \multicolumn{9}{|c|}{ Fast-food consumption (meals/wk) } \\
\hline None & Ref & & Ref & & Ref & & Ref & \\
\hline Any & 2.24 & $1.65,2.83$ & 2.13 & $1.54,2.71$ & 2.03 & $1.44,2.62$ & 2.04 & $1.45,2.63$ \\
\hline
\end{tabular}

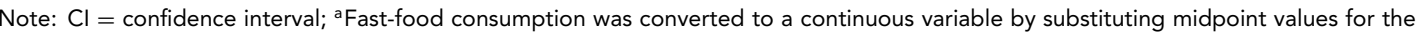
range provided in each ordinal response category $(0,1.5,3.5,7) ;{ }^{b}$ Unadjusted model; ${ }^{c}$ Adjusted for sex, age, race, income, and

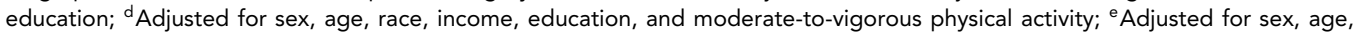
race, income, education, moderate-to-vigorous physical activity, and fast-food restaurant density in the residential neighborhood.

associated with a 2.17 unit greater BMI (95\% CI: 1.55, 2.79); 3-4 times per week was associated with a 2.25 unit greater BMI (95\% CI: 1.10, 3.40); and 5 or more times per week was associated with a 3.12 unit greater BMI (95\% CI: $1.42,4.83)$. When adjusting for potential confounders in sequential models, the association between more fast-food and greater BMI was attenuated but remained significant in linear trend tests for all models $(p s<.05)$.

When expressing fast-food consumption as a binary variable (none as the reference), any consumption of fastfood was associated with a 2.24 unit greater BMI (95\% CI: $1.65,2.83)$. Inclusion of potential confounders in sequential models slightly attenuated the overall magnitude of the association; however, all models retained statistical significance $(p s<.001)$.

\section{Discussion}

The results of this study suggest that genetic factors play an important role in the observed association between fastfood consumption and BMI. Although the individual GEE twin analyses showed statistically significant associations between BMI and fast-food consumption regardless of the expression of the fast-food consumption variable, the association was not seen when examining the within-pair effects in the overall or MZ twin-pair differences models. Because the twin-pair differences models control for shared environment and genetic characteristics, observing a significant association in the GEE models but not the twin-pair differences models suggests that the association between fast-food consumption and BMI was driven by shared environment and genetic factors among twins. Further, that the association was observed within $\mathrm{DZ}$, but not $\mathrm{MZ}$, pairs suggests that the individual-level association between fastfood consumption and BMI is mediated by genetic factors, because DZ pairs differ genetically and MZ pairs do not.

Previous studies have investigated how external factors might influence the fast-food and BMI association. Such factors include fast-food, fruit, and vegetable prices in the local environment (Morrissey et al., 2014), car ownership (Inagami et al., 2009), family income (Beydoun et al., 2008), family demographics (Meyer et al., 2014), and home and family environment (Berge et al., 2014). Our study therefore adds to the literature by estimating how genetic and shared environmental factors might influence the fast-food and BMI association.

The current study partially supports the findings of Nelson et al. that both genetic and environmental factors influence behavior (Nelson et al., 2006). Both studies provide evidence for the presence and influence of genetic factors in fast-food consumption. During the third wave of data collection, the twins in the Add Health study were 18-27 years of age, allowing the authors to stratify their results by twins still living together and twins living separately. 
In a cross-sectional analysis, $\mathrm{MZ}$ twins living apart had smaller correlations in BMI than MZ twins living together, and DZ twins living apart had smaller correlations in fastfood consumption than DZ twins living together, suggesting that adult home environment played a role in determining both BMI and fast-food consumption among individuals post-adolescence (Nelson et al., 2006). However, if genetics played no role in determining BMI and fast-food consumption, we would expect to see the same results for $M Z$ and DZ twins. The difference in findings between MZ and DZ twins is therefore suggestive of the influence of genetics.

Additionally, the Add Health data is longitudinal by design, so the authors were able to assess changes in BMI. In the longitudinal analysis, twins living apart had greater differences in the changes in BMI and fast-food consumption, regardless of their zygosity; however, this difference was only statistically significant for BMI change among $\mathrm{MZ}$ twins (Nelson et al., 2006). Again, the differences in results between MZ and DZ twins are suggestive of a genetic influence, a finding that is supported by the results of our current study.

\section{Strengths and Limitations}

The main strength of this study is the use of a large sample of adult twins from a community-based registry. The twin design allows for the control of confounding due to unmeasured genetic and shared childhood environment factors. Because of this, twin-difference analysis can yield quasi-causal inferences that are the best approximation to a randomized experimental design (Turkheimer \& Harden, 2014). The use of adults allows for a study population that has control over their dietary choices, unlike many previous studies which have focused on children and adolescents (Powell et al., 2010; St-Onge et al., 2003). Further, our study took the added step of controlling for fast-food restaurant density around the residential neighborhood as a measure of fast-food access.

Estimating the additive genetic, common environment, and unique environment components using the classical twin method poses a minor limitation in that it assumes that the proportion of variance in phenotype due to shared environment $(\mathrm{C})$ is the same for $\mathrm{MZ}$ and $\mathrm{DZ}$ twins (Grayson, 1989; Rijsdijk \& Sham, 2002), and because it further assumes the absence of gene-environment interactions and correlations (Purcell, 2002; Rijsdijk \& Sham, 2002). Also, the use of twins also cannot control for all behaviors, especially those that are influenced by events occurring after twins have left their parental household.

The cross-sectional design limits our ability to draw causal inferences because it does not guarantee the correct temporal order of events. As both BMI and fast-food consumption were measured at the same point in time, it is possible that BMI level preceded fast-food consumption. In addition, the use of BMI as an endpoint is problematic because BMI is a result of cumulative consumption and physical activity habits.

Related measures of recent fast-food consumption may not be appropriate for examining the fast-food and BMI relationship. Further, fast-food consumption was selfreported and recorded as an ordered categorical variable, thus there is potential for measurement bias, and transforming it into a continuous variable may have affected the statistical tests. Finally, the racial makeup of the UWTR is not representative of the U.S. population as a whole, limiting the generalizability of our results. However, the demographic characteristics of the UWTR are generally representative of residents of Washington State, so the results are relatively generalizable at the state level.

\section{Conclusion}

The results of this study suggest that genetic factors play a role in the correlation between fast-food consumption and BMI. Future research should combine twin data with longitudinal or gene-environment interaction studies to further explore this association. This will strengthen our ability to make causal inferences about the relationship between dietary habits, obesity, and genetics.

\section{Acknowledgments}

The authors acknowledge and thank Ally Avery (Scientific Program Manager) and the entire University of Washington Twin Registry staff for their diligent work in data collection, and the twins for taking part in the Registry. This work was supported in part by a grant from the National Institutes of Health (R01 AG042176 to G. Duncan). The National Institutes of Health played no role in the study design; the collection, analysis, or interpretation of data; the drafting of this manuscript; or the decision to submit it for publication.

\section{References}

Afari, N., Noonan, C., Goldberg, J., Edwards, K., Gadepalli, K., Osterman, B., ... Evanoff, C. (2006). University of Washington twin registry: Construction and characteristics of a community-based twin registry. Twin Research and Human Genetics, 9, 1023-1029.

Ahmad, S., Rukh, G., Varga, T. V., Ali, A., Kurbasic, A., Shungin, D., ... Franks, P. W. (2013). Gene x physical activity interactions in obesity: Combined analysis of 111,421 individuals of European ancestry. PLoS Genetics, 9, e1003607.

Berge, J. M., Wall, M., Larson, N., Forsyth, A., Bauer, K. W., \& Neumark-Sztainer, D. (2014). Youth dietary intake and weight status: Healthful neighborhood food environments enhance the protective role of supportive family home environments. Health \& Place, 26, 69-77.

Beydoun, M. A., Powell, L. M., \& Wang, Y. (2008). The association of fast food, fruit and vegetable prices with dietary intakes among US adults: Is there modification by family income? Social Science \& Medicine, 66, 2218-2229. 
Boomsma, D., Busjahn, A., \& Peltonen, L. (2002). Classical twin studies and beyond. Nature Reviews Genetics, 3, 872882.

Carlin, J. B., Gurrin, L. C., Sterne, J. A., Morley, R., \& Dwyer, T. (2005). Regression models for twin studies: A critical review. International Journal of Epidemiology, 34, 10891099.

Cauchi, S., Stutzmann, F., Cavalcanti-Proenca, C., Durand, E., Pouta, A., Hartikainen, A. L., ... Froguel, P. (2009). Combined effects of MC4R and FTO common genetic variants on obesity in European general populations. Journal of Molecular Medicine, 87, 537-546.

Centers for Disease Control and Prevention. (2014). Obesity and overweight for professionals: Data and statistics: U.S. obesity trends. Atlanta, GA: Author. Retrieved from http://www.cdc.gov/obesity/data/trends.html

Choquet, H., \& Meyre, D. (2011). Genetics of obesity: What have we learned? Current Genomics, 12, 169-179.

Colley, R. C., Hills, A. P., King, N. A., \& Byrne, N. M. (2010). Exercise-induced energy expenditure: Implications for exercise prescription and obesity. Patient Education and Counseling, 79, 327-332.

Comuzzie, A. G., \& Allison, D. B. (1998). The search for human obesity genes. Science, 280, 1374-1377.

Corella, D., Ortega-Azorin, C., Sorli, J. V., Covas, M. I., Carrasco, P., Salas-Salvado, J., ... Estruch, R. (2012). Statistical and biological gene-lifestyle interactions of MC4R and FTO with diet and physical activity on obesity: New effects on alcohol consumption. PloS One, 7, e52344.

Cutler, G. J., Flood, A., Hannan, P. J., Slavin, J. L., \& NeumarkSztainer, D. (2012). Association between major patterns of dietary intake and weight status in adolescents. The British Journal of Nutrition, 108, 349-356.

Dubois, L., Ohm Kyvik, K., Girard, M., Tatone-Tokuda, F., Perusse, D., Hjelmborg, J., ... Martin, N. G. (2012). Genetic and environmental contributions to weight, height, and BMI from birth to 19 years of age: An international study of over 12,000 twin pairs. PloS One, 7, e30153.

Eisen, S., Neuman, R., Goldberg, J., Rice, J., \& True, W. (1989). Determining zygosity in the Vietnam era twin registry: An approach using questionnaires. Clinical Genetics, 35, 423432.

Elks, C. E., den Hoed, M., Zhao, J. H., Sharp, S. J., Wareham, N. J., Loos, R. J., ... Ong, K. K. (2012). Variability in the heritability of body mass index: A systematic review and meta-regression. Frontiers in Endocrinology, 3, 29.

Garber, C. E., Blissmer, B., Deschenes, M. R., Franklin, B. A., Lamonte, M. J., Lee, I. M., ... American College of Sports Medicine. (2011). American college of sports medicine position stand. quantity and quality of exercise for developing and maintaining cardiorespiratory, musculoskeletal, and neuromotor fitness in apparently healthy adults: Guidance for prescribing exercise. Medicine and Science in Sports and Exercise, 43, 1334-1359.

Gordon-Larsen, P., Nelson, M. C., Page, P., \& Popkin, B. M. (2006). Inequality in the built environment underlies key health disparities in physical activity and obesity. Pediatrics, 117, 417-424.
Grayson, D. (1989). Twins reared together -- Minimizing shared environmental-effects. Behavior Genetics, 19, 593604.

Heitmann, B. L., Kaprio, J., Harris, J. R., Rissanen, A., Korkeila, M., \& Koskenvuo, M. (1997). Are genetic determinants of weight gain modified by leisure-time physical activity? A prospective study of finnish twins. The American Journal of Clinical Nutrition, 66, 672-678.

Inagami, S., Cohen, D. A., Brown, A. F., \& Asch, S. M. (2009). Body mass index, neighborhood fast food and restaurant concentration, and car ownership. Journal of Urban Health, $86,683-695$.

Larson, N., Neumark-Sztainer, D., Laska, M. N., \& Story, M. (2011a). Young adults and eating away from home: Associations with dietary intake patterns and weight status differ by choice of restaurant. Journal of the American Dietetic Association, 111, 1696-1703.

Larson, N., Neumark-Sztainer, D., Story, M., van den Berg, P., \& Hannan, P. J. (2011b). Identifying correlates of young adults' weight behavior: Survey development. American Journal of Health Behavior, 35, 712-725.

Lee, H. J., Kim, I. K., Kang, J. H., Ahn, Y., Han, B. G., Lee, J. Y., ... Song, J. (2010). Effects of common FTO gene variants associated with BMI on dietary intake and physical activity in koreans. Clinica Chimica Acta; International Journal of Clinical Chemistry, 411, 1716-1722.

McCaffery, J. M., Papandonatos, G. D., Bond, D. S., Lyons, M. J., \& Wing, R. R. (2009). Gene X environment interaction of vigorous exercise and body mass index among male vietnam-era twins. The American Journal of Clinical Nutrition, 89, 1011-1018.

Meyer, K. A., Guilkey, D. K., Ng, S. W., Duffey, K. J., Popkin, B. M., Kiefe, C. I., . . G Gordon-Larsen, P. (2014). Sociodemographic differences in fast food price sensitivity. JAMA Internal Medicine, 174, 434-442.

Min, J., Chiu, D. T., \& Wang, Y. (2013). Variation in the heritability of body mass index based on diverse twin studies: A systematic review. Obesity Reviews, 14, 871-882.

Morrissey, T. W., Jacknowitz, A., \& Vinopal, K. (2014). Local food prices and their associations with children's weight and food security. Pediatrics, 133, 422-430.

Mustelin, L., Silventoinen, K., Pietilainen, K., Rissanen, A., \& Kaprio, J. (2009). Physical activity reduces the influence of genetic effects on BMI and waist circumference: A study in young adult twins. International Journal of Obesity, 33, 29-36.

National Task Force on the Prevention and Treatment of Obesity. (2000). Overweight, obesity, and health risk. Archives of Internal Medicine, 160, 898-904.

Nelson, M. C., Gordon-Larsen, P., North, K. E., \& Adair, L. S. (2006). Body mass index gain, fast food, and physical activity: Effects of shared environments over time. Obesity, 14, 701-709.

Neumark-Sztainer, D., Wall, M., Larson, N. I., Eisenberg, M. E., \& Loth, K. (2011). Dieting and disordered eating behaviors from adolescence to young adulthood: Findings from a 10-year longitudinal study. Journal of the American Dietetic Association, 111, 1004-1011. 
Neumark-Sztainer, D., Wall, M., Story, M., \& Standish, A. R. (2012). Dieting and unhealthy weight control behaviors during adolescence: Associations with 10-year changes in body mass index. The Journal of Adolescent Health: Official Publication of the Society for Adolescent Medicine, 50, 80-86.

O'Rahilly, S., \& Farooqi, I. S. (2008). Human obesity: A heritable neurobehavioral disorder that is highly sensitive to environmental conditions. Diabetes, 57, 2905-2910.

Perusse, L., Rankinen, T., Rauramaa, R., Rivera, M. A., Wolfarth, B., \& Bouchard, C. (2003). The human gene map for performance and health-related fitness phenotypes: The 2002 update. Medicine and Science in Sports and Exercise, $35,1248-1264$.

Powell, L. M., Chaloupka, F. J., \& Bao, Y. (2007). The availability of fast-food and full-service restaurants in the United States: Associations with neighborhood characteristics. American Journal of Preventive Medicine, 33, S240-245.

Powell, L. M., Han, E., \& Chaloupka, F. J. (2010). Economic contextual factors, food consumption, and obesity among U.S. adolescents. The Journal of Nutrition, 140, 1175-1180.

Purcell, S. (2002). Variance components models for geneenvironment interaction in twin analysis. Twin Research, 5, 554-571.

Rampersaud, E., Mitchell, B. D., Pollin, T. I., Fu, M., Shen, H., O’Connell, J. R., ... Snitker, S. (2008). Physical activity and the association of common FTO gene variants with body mass index and obesity. Archives of Internal Medicine, 168, 1791-1797.

Rijsdijk, F. V., \& Sham, P. C. (2002). Analytic approaches to twin data using structural equation models. Briefings in Bioinformatics, 3, 119-133.

Roberto, C. A., Hoffnagle, E., Bragg, M. A., \& Brownell, K. D. (2010). An observational study of consumer use of fastfood restaurant drive-through lanes: Implications for menu labelling policy. Public Health Nutrition, 13, 1826-1828.

Scott, R. A., Bailey, M. E., Moran, C. N., Wilson, R. H., Fuku, N., Tanaka, M., ... Pitsiladis, Y. P. (2010). FTO genotype and adiposity in children: Physical activity levels influence the effect of the risk genotype in adolescent males. European Journal of Human Genetics, 18, 1339-1343.

Sonestedt, E., Roos, C., Gullberg, B., Ericson, U., Wirfalt, E., \& Orho-Melander, M. (2009). Fat and carbohydrate intake modify the association between genetic variation in the FTO genotype and obesity. The American Journal of Clinical Nutrition, 90, 1418-1425.

Spitz, E., Moutier, R., Reed, T., Busnel, M. C., Marchaland, C., Roubertoux, P. L., ... Carlier, M. (1996). Comparative diagnoses of twin zygosity by SSLP variant analysis, questionnaire, and dermatoglyphic analysis. Behavior Genetics, 26, 55-63.

St-Onge, M. P., Keller, K. L., \& Heymsfield, S. B. (2003). Changes in childhood food consumption patterns: A cause for concern in light of increasing body weights. The American Journal of Clinical Nutrition, 78, 1068-1073.

Strachan, E., Hunt, C., Afari, N., Duncan, G., Noonan, C., Schur, E., ... Buchwald, D. (2013). University of Washington twin registry: Poised for the next generation of twin research. Twin Research and Human Genetics, 16, 455-462.

Torgersen, S. (1979). The determination of twin zygosity by means of a mailed questionnaire. Acta Geneticae Medicae Et Gemellologiae, 28, 225-236.

Turkheimer, E., \& Harden, K. (2014). Behavior genetic research methods: Testing quasi-causal hypotheses using multivariate twin data. In H. Reis \& C. Judd (Eds.), Handbook of research methods in social and personality psychology (2nd ed., pp. 159-187). Cambridge, UK: Cambridge University Press.

US Department of Health and Human Services. (2009). National Health and Nutrition Examination Survey Data, 2007-2008. Hyattsville, MD: National Center for Health Statistics, Centers for Disease Control and Prevention, and US Department of Health and Human Services.

Vimaleswaran, K. S., Tachmazidou, I., Zhao, J. H., Hirschhorn, J. N., Dudbridge, F., \& Loos, R. J. (2012). Candidate genes for obesity-susceptibility show enriched association within a large genome-wide association study for BMI. Human Molecular Genetics, 21, 4537-4542. 